\title{
Situation, Challenges, and Countermeasures of Home-Based Healthcare Service Supply and Demand in China
}

\author{
Jingjing Sun'; Yalu Zhang'; Xinhui Zhang'; Xinming Song'; Gong Chen ${ }^{1, *}$
}

According to the Seventh National Census of China, the population of adults aged 65 and above will be 190 million in 2020 (13.5\% of the total population). As the "post-60s" group born at the second childbirth peak reaches retirement age, the growth rate of the population of older adults will accelerate significantly. By 2030, the proportion of older population (aged 65 and above) will reach about $17 \%$, and the growth rate of the population aged 80 and above will be even more pronounced. Greater age is associated with more comorbidities and chronic diseases. It is estimated that $46 \%$ of older adults in China suffer from multiple diseases and $38 \%$ suffer from functional impairment (1-2). With a rapidly aging population and longer life expectancy, the incidence of chronic diseases, disabilities, and functional impairment are increasing dramatically, posing new challenges to our society's healthcare system and healthcare expenditures.

\section{THE CURRENT SITUATION OF HOME-BASED HEALTHCARE SERVICE IN CHINA}

Home-based healthcare is a response to the need for healthcare services for the special groups (e.g., the oldest-old population or older adults with disabilities, with chronic diseases, or with needs of follow-up healthcare services after being discharged from the hospitals). Studies have shown that home-based healthcare in Japan and the United States can effectively alleviate the shortage of inpatient beds in hospitals, save medical insurance funds, and reduce the cost of seeking medical treatment for patients living in remote areas (3-4).

In China, home-based healthcare services have been provided in Beijing, Shanghai, Shenzhen, Jinan and other places, including three types of services - home visits, home care, and home sickbeds ${ }^{*}$ provided by community health service centers, public hospitals, and private medical institutions (5). These medical institutions differ in their service delivery, service recipients, and payment methods. According to the Chinese Longitudinal Healthy Longevity Survey (CLHLS) 2018 data, 34.3\% of older adults (aged 65 and above) were able to access home visiting services, while as many as $81.8 \%$ of older adults desired home visiting services that their communities provided. As shown in Table 1, such significant gaps of unmet needs existed across genders, age groups, types of household registration (hukou), living arrangements, daily living functioning, health insurance coverage, and residential area.

In 2020, the National Health Commission and the National Administration of Traditional Chinese Medicine issued the Notice on Strengthening HomeBased Healthcare Services for The Older Adults, which called for further increasing the supply of home-based healthcare services for the older adults and precisely matching the diverse urgent medical service needs of the older adults. However, compared with the countries in Europe, the United States, Japan, and many other countries, China's home healthcare services are still in their exploratory stage, and face a series of challenges. The rest of this paper will explicitly discuss the challenges from both the demand and the supply sides, and in the end provide some recommendations for future policymaking in China.

\section{THE CHALLENGES FROM DEMAND}

First, the demand for home-based healthcare services for the older adults is diverse. At present, offered services are mostly limited to basic services such as injection, medication change, urinary catheterization, blood pressure (blood glucose) monitoring, etc. In addition to the above services, psychological counselling, remote health monitoring, home sickbeds,

\footnotetext{
* Notes: Home sickbed is a bed designed to help patients recover according to the treatment needs and living habits of patients and uses the family and home as the treatment and nursing place, which can meet various treatment, rehabilitation, and nursing needs.
} 
TABLE 1. Supply and demand of home healthcare for Chinese older adults in $2018(\mathrm{~N}=15,720)$.

\begin{tabular}{|c|c|c|c|c|c|}
\hline \multirow[b]{2}{*}{ Variables } & & \multicolumn{4}{|c|}{ Home visiting services } \\
\hline & & \multirow{2}{*}{$\begin{array}{c}\begin{array}{c}\text { Available in } \\
\text { community (\%) }\end{array} \\
34.26\end{array}$} & \multirow[t]{2}{*}{$P$} & $\begin{array}{l}\text { Expect community } \\
\text { to provide (\%) }\end{array}$ & \multirow[t]{2}{*}{$P$} \\
\hline Overall & & & & 81.84 & \\
\hline \multirow[t]{2}{*}{ Gender } & Male & 34.33 & 0.977 & 81.44 & 0.837 \\
\hline & Female & 34.21 & & 82.15 & \\
\hline \multirow[t]{3}{*}{ Age, years } & $65-74$ & 33.66 & 0.870 & 82.25 & 0.328 \\
\hline & $75-84$ & 32.08 & & 80.23 & \\
\hline & $\geq 85$ & 35.63 & & 82.51 & \\
\hline \multirow[t]{2}{*}{ Household registration } & Urban & 28.88 & $<0.001$ & 76.24 & $<0.001$ \\
\hline & Rural & 36.23 & & 83.93 & \\
\hline \multirow[t]{3}{*}{ Living arrangement } & With family member(s) & 34.08 & $<0.001$ & 81.64 & $<0.050$ \\
\hline & Living alone & 32.16 & & 82.27 & \\
\hline & In an institution & 46.65 & & 82.27 & \\
\hline \multirow[t]{3}{*}{ Limited in activities } & Strongly limited & 36.27 & 0.235 & 80.76 & 0.235 \\
\hline & Limited & 37.68 & & 83.59 & \\
\hline & Not limited & 32.53 & & 81.41 & \\
\hline \multirow[t]{2}{*}{ Basic medical Insurance coverage } & Yes & 34.73 & $<0.001$ & 82.42 & $<0.001$ \\
\hline & No & 31.42 & & 76.86 & \\
\hline \multirow[t]{2}{*}{ Commercial medical insurance } & Yes & 44.86 & $<0.001$ & 82.08 & 0.446 \\
\hline & No & 34.28 & & 81.7 & \\
\hline \multirow[t]{4}{*}{ Area } & East & 38.05 & $<0.001$ & 81.31 & $<0.001$ \\
\hline & Central & 36.70 & & 85.77 & \\
\hline & West & 27.73 & & 83.61 & \\
\hline & Northeast & 16.77 & & 62.74 & \\
\hline
\end{tabular}

Note: The Chinese Longitudinal Healthy Longevity Survey gives the data of 2018, which is the latest publicly available data so far. With the introduction of policies and the development of the older adults' healthcare services in recent years, the data analysis results are likely to be underestimated.

and medical patrol are also in high demand by the home-based older adults (G).

Second, older adults may have a lower level of knowledge about home healthcare service but a high willingness to accept them. A survey on the demand for home-based healthcare services in Chaoyang District, Beijing Municipality showed that only $26.8 \%$ of older adults were aware of at least one home-based health service, while the proportion of older adults who were supportive of home-based health services were more than $70 \%$ (7). It is evident that older adults have high expectations for home healthcare services, but the lower awareness rate may have resulted in lower service utilization. The practice of Kumamoto City, Japan is worth referencing. The relevant medical administrative units are responsible for investigating the scope of home-based medical services and the receiving capacity of various medical institutions and then printing brochures according to the survey results to help patients understand the scope of home services and disposal process of various medical institutions (3).

\section{THE CHALLENGES FROM SUPPLY}

Compared to the challenges from demand, the challenges from supply are more complicated. First, the risk management system of home-based healthcare services is imperfect. The complex home environment imposes higher requirements for medical skills and improvisational abilities on medical personnel. The change of medical treatment location brings legal and safety risks beyond traditional medical treatment. Medical personnel are reluctant to provide services at home due to the lack of protection from laws and regulations. For example, due to the tension of the doctor-patient relationship and the fact that the current enforced Physician Law (2009 version) does not apply to home healthcare, medical professionals are 
concerned that some home healthcare practices may violate the law (8). Even if the revised draft of the Physician Law (2021 version) has been issued, most of the revised parts are related to the prevention of infectious diseases, and some situations may still not be suitable for home medical treatment. Referring to the relevant series of home care laws and systems of the United States, Canada, the Netherlands, and other countries, the Physicians Act should be revised according to China's local circumstances.

Second, there is a lack of institutions or organizations responsible for communication between various institutional departments, resulting in barriers to information transmission among hospitals, medical insurance institutions, and primary medical institutions. The provision of home-based healthcare services require close collaboration among relevant local government departments, hospitals, community health service centers, community resident committees, and other institutions. If the cooperation is not smooth, problems can arise, such as lack of understanding of patients' daily living habits by doctors, mismatch between the equipped medical personnel and the medical needs of residents, and inadequate understanding of the guidelines and policies of higher authorities. Japan's government has set up home-based health cooperation stations in each region, which are responsible for leading communication and cooperation between various departments, conveying the policies and guidelines of superior departments, and finding appropriate local implementation methods (3). Furthermore, the cooperation stations accurately grasp the local healthcare resources and establish a mechanism for mobile services in the region. These practices can be used as a reference for China.

Third, the economic security of home-based healthcare services is insufficient. For the service recipients, the lack of economic security is reflected in the fact that the provision of home medical services by hospitals is not covered by medical insurance and is paid for by the demand side (9). Innovative programs should be developed that can be used as models for other jurisdictions. The experience in Beijing can be used as a reference. Beijing Municipal Government has included medical expenses for on-site service in the medical insurance reimbursement program. At the same time, medical insurance reimbursement can be obtained by using home sickbeds, and the starting line of the reimbursement is reduced by $50 \%$. In the case of home care services, we can refer to the practice of
Japan, which connects care insurance with home care service and prioritize the use of care insurance to pay the expenses incurred by home care. Moreover, there is insufficient incentive for the medical personnel to provide home-based healthcare services. For example, such services in a community in the Bailong Street District of Fuzhou City are provided by the medical personnel from a nearby Chinese medicine hospital. These personnel regard home-based health visits and care as a public service activity and did not receive additional compensation for the service provision.

Fourth, the information-sharing mechanism of home-based healthcare services is insufficient. In 2013, the National Basic Public Health Service Program proposed to establish electronic health records for permanent residents in the jurisdiction. As of 2020, the filing rate of electronic health records exceeded $90 \%$. However, there is still a certain distance from the ideal information-sharing mechanism. For example, the information-sharing between electronic health records and hospital electronic medical records is inconvenient, resulting in the low utilization of electronic records. Some practices of local governments in China and valuable experiences from abroad are worth referencing. Chaoyang District of Beijing has built a regional information-based medical service platform to provide older adults, especially empty nesters whose children have left the home, with integrated continuous services including chronic disease management, medical treatment, rehabilitation, and healthcare. The platform helps to monitor older adults' health conditions and greatly improves the work efficiency of the community physicians. Additionally, the Japanese government has actively used information and communication technology (ICT) to build an interconnected information support system. Medical and professional nursing staff can use the platform to record or view the diagnosis, care plan, daily temperature change chart, and medication status of patients in home care at any time, which significantly improved service quality and the communication efficiency between medical and nursing staff and patients (10). Meanwhile, government departments can use the platform to achieve real-time supervision and effectively curb illegal acts such as abuse of older adults' personal and property rights.

Fifth, the personnel supply of home-based medical care services is insufficient. With the promotion of community family physician model, home-based healthcare services provided by primary medical institutions for the older adults and disabled at home 
are gradually increasing. According to the statistics of the National Health Commission, the number of general practitioners in China increased from 252,000 in 2017 to 365,000 in 2019 , with an average annual growth rate of $20 \%$. According to the long-term goal of having 5 general practitioners per 10,000 residents in 2030, it is expected to achieve this goal before 2025 (anticipated based on that China's total population will reach 1,450 million in 2030 estimated by the United Nations). China has significantly increased the number of general practitioners in poor areas through the implementation of the special post plan for general practitioners and the targeted admission medical education program for rural students. However, there is still a certain gap with the growing demand for health management. Meanwhile, the current personnel management system of medical and health institutions in China adopts a fixed staffing and work position system (according to the tasks undertaken by the government, enterprises, and institutions, determine the establishment of institutions and the number of personnel to streamline institutions and improve efficiency), which would further aggravate shortages of primary medical personnel if medical institutions are required to carry out home healthcare services (11). In addition to general practitioners and registered nurses, the family physician team needs more rehabilitation physicians, public health physicians, community nursing staff, and other medical staffs. However, due to the reasons of low wages, high labor intensity, low social recognition, and imperfect protection mechanisms (12), healthcare staff are not willing to engage in onsite medical and nursing services. The salary incentive to prevent personnel loss can learn from the practice of the United States, which takes $10 \%$ of the medical insurance quota as a subsidy for medical personnel (13).

Sixth, there are regional differences in the provision of home-based healthcare services. The provision of home healthcare services is closely related to socioeconomic development. More home-based health services are provided in economically developed areas. But it is difficult for older adults in remote areas to obtain such resources (Table 1). Regional differences are a global problem, even for Japan and the United States, where home-based care service have been relatively well developed. Telemedicine is recognized as the best way to solve this problem and achieve some medical equity. In 2015, with the guidance of the State Council on actively promoting the "Internet plus initiative" action, some companies providing telemedicine have gradually developed in China. For example, the website named "Good Doctor Online" can provide a number of remote services such as hospital/doctor information query, online consultation, post-diagnosis disease management, family medicine, and disease knowledge education. Although great improvements have been achieved, a series of problems, such as the inability to use medical insurance to pay for online consultations with doctors and the long delivery time of medications remains unresolved.

\section{VISION FOR HOME-BASED HEALTHCARE SERVICE IN CHINA}

The theme of the Plan of Health China 2030 is "Contribution and Shared Benefits, Achieve National Health". The provision of home-based healthcare services is one of the important ways to realize the strategy of healthy China. In the future, we should provide home-based healthcare for the entire population throughout their life cycle to improve national health. The core thought is to prioritize prevention, paying equal attention to traditional Chinese and western medicine.

There is a long way to go to implement home-based healthcare in China. However, it can be seen from the introduction of the strengthening care policy for older adults that China's government has been paying much attention to and committing to encouraging the development of home-based healthcare. Furthermore, based on the Plan of Health China 2030, the vision for home healthcare services should adhere to the following principles.

An excellent home-based healthcare system should focus on people's health. The idea of taking people's health as the central priority emphasizes the transformation from "treatment first" to "prevention first". Thus, home-based healthcare systems should focus on keeping people healthy by preventing illness and injury, postponing illness, and providing medical and nursing services to reduce the impact of disease and improve quality of life.

It is necessary to provide home healthcare services for the whole life cycle of the entire population. This goal needs to be achieved step by step. At present, we need to prioritize the limited resources to meet the needs of vulnerable groups. In the future, we hope to provide home healthcare services that meet the diversified health needs of the whole population across 
the entire life cycle through the government and the market to promote the health literacy of the entire people.

It is time to realize the scientific development of home-based healthcare services. We need to grasp the development rules of health to provide health services. Furthermore, we should build a home-based healthcare service supply coordinated with the national medical and health service system to promote the quality and efficiency of home healthcare services.

We will promote the equalization of essential home healthcare services. We expect to make full use of technological innovation and information technology to gradually narrow the differences in essential home healthcare services between urban and rural areas, regions, and groups, and move towards universal coverage and promote health equity.

\section{RECOMMENDATIONS FOR IMPROVEMENT OF HOME-BASED HEALTHCARE SERVICE IN CHINA}

At present, the main obstacles encountered in developing home-based healthcare services in China can be summarized as follows: (1) The inaccurate identification of effective demand; (2) The imbalance of the supply structure; (3) The lack of integration of factors.

Focused on the vision of home healthcare that we are trying to establish, the construction of a homebased healthcare service system with local situations needs to make efforts from both sides of supply and demand at the same time.

First, a deep understanding of effective demand is a prerequisite for providing accurate home-based healthcare services. It is necessary to establish a comprehensive evaluation standard for home-based healthcare service needs, to strengthen the collection of such service information for older adults, regularly carry out older adults' home service needs assessment, to specify the quantity and type of need, to allocate related resources and services according to requirements, and to improve the accuracy of services supply and subsidies.

Second, the system of home-based healthcare services needs to be improved. China urgently needs to improve the medical risk management mechanism and set up intermediary agencies responsible for interagency communication and cooperation. The relevant industry norms, service standards, price mechanism, and risk quality control need to be further clarified and unified to become a legal guarantee and code of conduct for medical personnel to provide home healthcare. In addition, the health administration department should establish a particular institution to strengthen the communication and collaboration among various departments.

Third, the supply of home healthcare services needs to be significantly improved to meet the effectual demand. Its development focuses on improving talent allocation and economic security.

It is crucial to fully realize and develop existing human resources and improve the management norms of medical personnel. In order to increase the number of personnel, we should fully utilize the doctors and nurses in secondary hospitals, industrial hospitals (plants for coal, steel, etc.), and traditional Chinese medicine hospitals with few patients to form a family doctor team; in addition, medical institutions should establish salary and position promotion incentive mechanisms to prevent personnel loss. Regarding personnel quality, it is necessary to divide the types of home healthcare services and the operational functions of medical staff based on needs and give general practitioners the right of two-way referral (not only transfer patients from lower-level hospitals to higherlevel hospitals but also transfer patients from higherlevel hospitals to lower-level hospitals) and green channel for medical treatment (a service package that includes expert outpatient services, hospitalization arrangements, operation arrangements, post-treatment follow-ups, expert return visits, etc., to facilitate patients with urgent medical needs to enjoy medical resources first) to improve the social status of family doctors. Meanwhile, we should pay attention to the role of nurses and encourage them to undertake doorto-door nursing, team management, and other work.

Home-based healthcare service programs should be linked with basic medical insurance and long-term care insurance to strengthen financial protection of homebased healthcare. It is also necessary to improve people's utilization of primary health services appropriately (e.g., properly reducing the starting line of the reimbursement).

Fourth, it is crucial to improve the informationsharing mechanism and the development of Internet medicine to promote health equality. The ideal information-sharing mechanism should contain the health monitoring data reported by patients and their family members, the living environment and health information provided by the community, and patient's 
medical records in hospitals. It is urgent to use modern information technology to build a health informationsharing platform based on electronic health records and hospital electronic medical records, which can not only help the community physicians to monitor older adults' health conditions and dramatically improve the work efficiency but also help governmental departments to implement real-time supervision. Meanwhile, it is necessary to promote the development of telemedicine, which can improve the uneven distribution of regional medical resources. Relevant policy-making and patient demand are the two determinants of the development of telemedicine. Policymakers need to clarify the types of diseases to set up treatment norms to promote the participation of physical hospitals and internet enterprises. Patients' needs include people's needs for health maintenance (especially living in remote areas), the need for medical insurance to cover internet medical expenses, and the use habits and convenience of internet medical treatment. Solving the above problems can further promote the development of Internet medicine.

As an essential part of primary medical services and a way to actively deal with population aging, homebased healthcare services have effectively met the people's multilevel medical and health needs. Therefore, we hope to keep people healthy at home as much as possible by promoting home-based healthcare services.

Conflicts of Interest: No conflicts of interest declared.

Funding: National Social Science Fund of China (Grant No.20ZDA076).

doi: $10.46234 / \mathrm{ccdcw} 2021.209$

\#Corresponding author: Gong Chen, chengong@pku.edu.cn.

${ }^{1}$ Peking University Institute of Population Research, Beijing, China.

Submitted: September 12, 2021; Accepted: September 22, 2021

\section{REFERENCES}

1. Chen H, Cheng ML, Zhuang Y, Broad JB. Multimorbidity among middle-aged and older persons in urban China: prevalence, characteristics and health service utilization. Geriatr Gerontol Int 2018;
18:1447 - 52. http://dx.doi.org/10.1111/ggi.13510.

2. Zhang R, Lu Y, Shi LY, Zhang SL, Chang F. Prevalence and patterns of multimorbidity among the elderly in China: a cross-sectional study using national survey data. BMJ Open 2019;9(8):e024268. https:// bmjopen.bmj.com/content/9/8/e024268.

3. Li NN, Zhao J. The regional integration of home medical care under the comprehensive medical care system in Japan. J Jpn Language Study Res 2019;(3):39-46. https://kns.cnki.net/KXReader/Detail?TIMEST AMP $=637669628156307621 \& D B C O D E=C J F D \& T A B L E N a m e=C J F$ DLAST2018\&FileName $=$ XNLX201804025\&RESULT $=1 \& S I G N=r m$ \%2bQojPMcWlmG\%2bU3ZgY0dVduujE\%3d. (In Chinese).

4. Yang XJ, Ding HS, Du LX. Implication from the American program of all-inclusive care for the elderly. Chin Health Resour 2016;19(4):354 7. http://dx.doi.org/10.13688/j.cnki.chr.2016.15377. (In Chinese).

5. Yao NL. Research on the service mode of home care medicine in China. Chin Gener Pract 2020;23(12):1455 - 8. http://dx.doi.org/10.12114/ j.issn.1007-9572.2019.00.487. (In Chinese).

6. Xiao P, Song S, Zhu L, Wu X, Wang S, Gao YJ. Analysis on the statusquo of demand and supply of community-based medical services under the mode of medical integration. Health Econom Res 2019;36 (6):28-31. https://kns.cnki.net/KXReader/Detail?TIMESTAMP=637 $669634495952201 \& D B C O D E=C J F D \&$ TABLEName $=$ CJFDLAST20 19\&FileName=WSJJ201906010\&RESULT $=1 \& S I G N=$ DooZIXUow 9 3Clxrk7px5fHpXYS0\%3d. (In Chinese).

7. Hu SX, Bai X, Rao FY, Zhang S, Lv CH, Zuo YP, et al. Demand of elderly for home-based medical care services and its influencing factors in Chaoyang district of Beijing City. Med Soc 2018;31(7):77 - 80, 86. http://dx.doi.org/10.13723/j.yxysh.2018.07.025. (In Chinese).

8. Chen T, Yao NL, Su MZ, Nong S, Bai M, Ma ZY. Challenges of home-based medical care in China: a telephone interview from the perspectives of home care providers. Chin Gener Pract 2020;23 (12):1459 - 65. http://dx.doi.org/10.12114/j.issn.1007-9572.2020.00. 214. (In Chinese).

9. Bai M, Ge HT, Yao NL, Chen T, Wu BX. Home health care delivery models in China: an exploratory comparative study. Chin Gener Pract 2021;24(19):2379 - 84. http://dx.doi.org/10.12114/j.issn.1007-9572. 2021.00.229. (In Chinese).

10. Ren Y, Liu L, Shi J. Japan's Integration of Medical Care and LongTerm Care: Mechanism, Characteristics and Inspiration. Journal of Tianjin Administration Institute, 2021,23(4):87-95. https://kns.cnki. net $/$ kcms $/$ detail/detail.aspx?dbcode=CJFD\&dbname=CJFDLAST202 1 \&filename $=$ TJXZ202104009\&uniplatform $=$ NZKPT\& $v=c P h 4 T h \% 25$ mmd2BemjPPiuyM2DqJ3D6vRvsf51\%25mmd2Fke3OTJz6pEUGMJ 0zXfQo\%25mmd2BjwFFY\%25mmd2FeeLSl7. (In Chinese).

11. Hao XN, Bo T, Zheng YH, Liu Z. Analysis of the status and development path of home medical care services. Health Econom Res 2020;37(2):7-9. https://kns.cnki.net/KXReader/Detail?TIMESTAMP= $637669637625696391 \& D B C O D E=C J F D \& T A B L E N a m e=C J F D L A S$ T2020\&FileName $=$ WSJJ202002004\&RESULT $=1 \& S I G N=$ PPX0TPO g5vd3AMVtgX6PhDayjD4\%3d. (In Chinese).

12. Xie WY. Ethical advantage, problem analysis and countermeasures of family doctor service mode of the "medical-nursing combined" model. Chin Med Ethics 2018;31(4):519 - 24. http://dx.doi.org/10.12026/ j.issn.1001-8565.2018.04.24. (In Chinese).

13. Qiu S, Liu JR, Wu SJ. Historical evolution and enlightenment of the patient-centered medical home in America. Chin Gener Pract 2015; 18(22):2623 - 7. http://dx.doi.org/10.3969/j.issn.1007-9572.2015.22. 002. (In Chinese). 